\title{
Role of specific DNA mutations in the peripheral blood of colorectal cancer patients for the assessment of tumor stage and residual disease following tumor resection
}

\author{
GREGOR NORCIC ${ }^{1}$, FRANC JELENC ${ }^{1}$, PETRA CERKOVNIK ${ }^{2}$, VIDA STEGEL ${ }^{2}$ and SRDJAN NOVAKOVIC ${ }^{2}$ \\ ${ }^{1}$ Clinical Department of Abdominal Surgery, University Medical Centre Ljubljana; ${ }^{2}$ Department of Molecular Diagnostics, \\ Institute of Oncology Ljubljana, 1000 Ljubljana, Slovenia
}

Received April 22, 2015; Accepted August 12, 2016

DOI: $10.3892 / \mathrm{ol} .2016 .5078$

\begin{abstract}
In the present study, the detection of tumor-specific KRAS proto-oncogene, GTPase $(K R A S)$ and B-Raf proto-oncogene, serine/threonine kinase $(B R A F)$ mutations in the peripheral blood of colorectal cancer (CRC) patients at all stages and adenomas was used for the estimation of disease stage prior to surgery and for residual disease following surgery. A total of $65 \mathrm{CRC}$ patients were enrolled. The primary tumor tested positive for the specific mutations (KRAS mutations in codons 12,13, 61, 117 or 146 and $B R A F$ mutations in codon 600 ) in 35 patients. In all these patients, the specimen of normal bowel resected with the tumor was also tested for the presence of the same mutations in order to exclude the germ-line mutations. Only patients who tested positive for the specific mutation in the primary tumor were included in further analysis for the presence of tumor-specific mutation in the peripheral blood. No statistically significant differences were found between the detection rates of tumor mutations in the blood and different tumor stages $(\mathrm{P}=0.491)$. However, statistically significant differences in the proportions of patients with detected tumor-specific DNA mutations in the peripheral blood were found when comparing the groups of patients with $\mathrm{R} 0$ and $\mathrm{R} 2$ resections $(\mathrm{P}=0.038)$. Tumor-specific DNA mutations in the peripheral blood were more frequently detected in the patients with an incomplete surgical clearance of the tumor due to macroscopic residual disease (R2 resections). Therefore, the study concludes that the follow-up of somatic $K R A S$ - and BRAF-mutated DNA in the peripheral blood of CRC patients may be useful in assessing the surgical clearance of the disease.
\end{abstract}

Correspondence to: Professor Srdjan Novakovic, Department of Molecular Diagnostics, Institute of Oncology Ljubljana, Zaloska 2, 1000 Ljubljana, Slovenia

E-mail: snovakovic@onko-i.si

Key words: colorectal cancer, KRAS, BRAF, CK20, peripheral blood, residual disease, staging

\section{Introduction}

Colorectal cancer (CRC) is the third most frequent cancer and the fourth most common cause of cancer-associated mortality globally, with an annual incidence of 17.2/100,000 people and an age-standardized mortality rate of $8.4 / 100,000$ people worldwide $(1,2)$. The preferred treatment option is complete surgical resection, yet in up to $30 \%$ of cases the cancer recurs either locally or as distant metastasis (2). In order to reduce the incidence of disease recurrences, chemotherapy or radiochemotherapy are indicated, in addition to surgery in certain patients. It has been shown that only patients with cancer that has spread to the local lymph nodes benefit from these additional treatment options (1). Therefore, appropriate pre- and post-operative tumor-node-metastasis (TNM) staging is crucial for the optimal treatment of CRC patients and for the estimation of their prognosis (1,3). Follow-up for several years after treatment is necessary for the early detection of disease recurrence (2).

Since surgery is the treatment of choice in CRC, the completeness of the surgical removal of the tumor is the most important treatment-related prognostic factor in CRC patients. The completeness of the surgical removal of the tumor is expressed in terms of the R category: R0 meaning the complete removal of the tumor, $\mathrm{R} 1$ meaning microscopic residual disease and R2 meaning macroscopic residual disease $(4,5)$.

The two most important prognostic factors (the stage of the disease at diagnosis and residual disease after surgical resection) are assessed by the pathohistological analysis of the resected tumor specimen. Clinical decisions regarding adjuvant treatment or follow-up after surgery are based on the pathohistological analysis of the removed specimen and are based on the probability of malignant tissue remaining in the patient (6). A more direct and effective method would be to introduce a biomarker that could measure the disease burden, as well as the residual disease, directly in the patient's body (7).

This idea has led to the search for a specific molecular marker in the peripheral blood for the detection of minimal residual disease after the primary treatment of CRC. The majority of investigated molecular markers have been tumor-associated membrane proteins, such as cytokeratin 20 (CK20), and 
tumor-specific DNA mutations, such as KRAS proto-oncogene, GTPase (KRAS) (8). The detection of minimal residual disease in the peripheral blood through the use of molecular markers has been shown to have an impact on a patient's prognosis in a number of studies, although the methods are not yet sufficiently standardized for clinical use (9-11).

The present study was aimed at determining the expression of CK20 and the presence of KRAS and B-Raf proto-oncogene, serine/threonine kinase $(B R A F)$ tumor-specific mutations in DNA isolated from the peripheral blood prior to and following surgery, in order to assess whether the serological markers can be used to determine the stage of the disease at diagnosis and the R status after surgery.

\section{Materials and methods}

Patients. The study was approved by the Republic of Slovenia National Medical Ethics Committee (Ljubljana, Slovenia). All patients made an informed decision to take part in the study and provided written consent. Patients were informed that the results of tests would not be disclosed to them, as they would not affect the standard treatment provided, to which all patients consented.

A total of 65 patients scheduled for elective surgery at University Medical Centre Ljubljana (Ljubljana, Slovenia) due to CRC or adenomas between July 2011 and January 2012 were enrolled into the study. The patients were staged into Union for International Cancer Control (UICC) TNM categories and stages according to the pre-operative staging results, intraoperative findings and pathohistological results of the resected specimens, as described previously (1). After surgery, the pathohistological analysis of the resected specimens was performed in a standard manner (3). The clearance of tumor tissue by surgery was expressed by $\mathrm{R}$ category based on surgery reports and pathohistological analysis of the resected specimen.

Samples. Formalin-fixed paraffin-embedded (FFPE) tumor tissue and matched normal tissue samples were obtained from each patient. The appropriate FFPE tumor and normal tissue block was selected by the pathologist, who also evaluated the percentage of tumor cells in the paraffin slides from the first and last hematoxylin and eosin (HE)-stained sections. Six consecutive non-colored FFPE sample cuts between the HE colored sections with the thickness of $10-\mu \mathrm{m}$ were prepared in an Eppendorf tube by the pathologist. Additionally, from each patient, the peripheral whole blood samples were collected immediately prior to the surgery and 5-7 days after the surgery. The whole blood samples were collected in 10-ml EDTA tubes and stored at $-80^{\circ} \mathrm{C}$. The samples $(1 \mathrm{ml})$ were centrifuged at $1,700 \times \mathrm{g}$ for $25 \mathrm{~min}$ at $4^{\circ} \mathrm{C}$ to obtain pellets (cells and cellular debris). These pellets were then used for DNA and RNA extraction

DNA isolation. For the DNA extraction, a QIAamp DNA FFPE kit (Qiagen, Hilden, Germany) was used according to the manufacturer's protocols. The DNA from the blood samples was extracted using an Arrow Blood DNA kit (NorDiag, Dublin, Ireland) according to the manufacturer's protocols. After the isolation, the DNA concentration was measured spectrophotometrically at 280/260 nm using a NanoDrop 2000c spectrophotometer (Thermo Fisher Scientific, Inc., Waltham, MA, USA).

RNA isolation. Total RNA was isolated from the blood using an miRNeasy Mini kit (Qiagen) according to the manufacturer's protocols. RNA was quantified using the NanoDrop spectrophotometer, and cDNA was synthesized from $500 \mathrm{ng}$ of the total RNA using the High-Capacity cDNA Reverse Transcription kit with RNase Inhibitor (Applied Biosystems; Thermo Fisher Scientific, Inc. Foster City, CA, USA), according to the manufacturer's protocols.

Determination of KRAS and BRAF mutations. Determination of $K R A S$ and $B R A F$ mutation status was performed using the KRAS/BRAF Mutation Analysis kit (EntroGen, Tarzana, CA, USA) for a quantitative polymerase chain reaction (qPCR) assay based on allele-specific PCR. The assay is designed to preferentially amplify mutant DNA even in samples that have mostly wild-type DNA. In the assay, an endogenous control gene is included in order to ensure that a sufficient amount of DNA is available for amplification. The detection of the amplification product is performed using fluorescent hydrolysis probes. The assay was performed according to the manufacturer's protocols, with $25 \mathrm{ng}$ DNA per reaction using an ABI7900 system (Applied Biosystems; Thermo Fisher Scientific, Inc.). For data analysis, the manufacturer's instructions were followed (EntroGen). The KRAS/BRAF Mutation Analysis kit includes primers and probes for detection of the 18 most common KRAS mutations in codons 12 , $13,61,117$ and 146, and a single $B R A F$ mutation in codon 600 (Table I).

Determination of CK2O gene expression. Reverse transcription-qPCR (RT-qPCR) was performed using a LightCycler 480 instrument (Roche Applied Science, Mannheim, Germany). The primers used for amplification of the target gene, CK20, and a housekeeping gene, glyceraldehyde 3-phosphate dehydrogenase (GAPDH), were as follows: CK20 forward, 5'-CTGAATAAGGTCTTTGATGACC-3' and reverse, 5'-ATGCTTGTGTAGGCCATCGA-3'; and GAPDH forward, 5'-GAAGGTGAAGGTCGGAGTC-3' and reverse, 5'-GAAGATGGTGATGGGATTTC-3', as described previously by Shen et al (12). RT-qPCR was set up in triplicate in 384-well plates and performed in $10-\mu 1$ reactions with 2X LightCycler 480 SYBR Green I Master (Roche Applied Science), $10 \mu \mathrm{M}$ of each primer (Applied Biosystems) and $300 \mathrm{ng}$ cDNA. The thermocycling conditions were as follows: $95^{\circ} \mathrm{C}$ for $10 \mathrm{~min}$, and 45 cycles of $95^{\circ} \mathrm{C}$ for $15 \mathrm{sec}, 60^{\circ} \mathrm{C}$ for $45 \mathrm{sec}$ and $72^{\circ} \mathrm{C}$ for $15 \mathrm{sec}$, followed by a melting curve construction by increasing the temperature from $65-95^{\circ} \mathrm{C}$ with a temperature transition rate of $0.1^{\circ} \mathrm{C} / \mathrm{sec}$. A melting curve analysis was performed to verify that the product consisted of a single amplicon. In each experiment, the control group consisted of a pool of RNA samples isolated from the whole blood of healthy volunteers. The data were analyzed by Roche LightCycler 480 software (Roche Applied Science) using the advanced relative quantification method, according to the manufacturer instructions, where the $\Delta \mathrm{Cq}$ values of a control group were used for normalization. 
Table I. List of KRAS and BRAF mutations covered by the KRAS/BRAF mutation analysis kit (EntroGen).

\begin{tabular}{|c|c|c|c|}
\hline Gene & Exon & Nt change & aa change \\
\hline \multirow[t]{18}{*}{$K R A S$} & \multirow[t]{7}{*}{2} & c. $34 \mathrm{G}>\mathrm{C}$ & p.Gly12Arg \\
\hline & & c. $34 \mathrm{G}>\mathrm{T}$ & p.Gly12Cys \\
\hline & & c. $34 \mathrm{G}>\mathrm{A}$ & p.Gly12Ser \\
\hline & & c. $35 \mathrm{G}>\mathrm{T}$ & p.Gly12Val \\
\hline & & c. $35 \mathrm{G}>\mathrm{C}$ & p.Gly12Ala \\
\hline & & c. $35 \mathrm{G}>\mathrm{A}$ & p.Gly12Asp \\
\hline & & c. $38 \mathrm{G}>\mathrm{A}$ & p.Gly13Asp \\
\hline & \multirow[t]{4}{*}{3} & c. $182 \mathrm{~A}>\mathrm{G}$ & p.Gln61Arg \\
\hline & & c. $183 \mathrm{~A}>\mathrm{C}$ & p.Gln61His \\
\hline & & c. $183 \mathrm{~A}>\mathrm{T}$ & p.Gln61His \\
\hline & & c. $182 \mathrm{~A}>\mathrm{T}$ & p.Gln61Leu \\
\hline & \multirow[t]{7}{*}{4} & c. $351 \mathrm{~A}>\mathrm{C}$ & p.Lys117Asn \\
\hline & & c. $351 \mathrm{~A}>\mathrm{T}$ & p.Lys117Asn \\
\hline & & c. $350 \mathrm{~A}>\mathrm{G}$ & p.Lys117Arg \\
\hline & & c. $349 \mathrm{~A}>\mathrm{G}$ & p.Lys117Glu \\
\hline & & c. $436 \mathrm{G}>\mathrm{A}$ & p.Ala146Thr \\
\hline & & c. $436 \mathrm{G}>\mathrm{C}$ & p.Ala146Pro \\
\hline & & c. $437 \mathrm{C}>\mathrm{T}$ & p.Ala146Val \\
\hline$B R A F$ & 15 & c. $1799 \mathrm{~T}>\mathrm{A}$ & p.Val600Glu \\
\hline
\end{tabular}

$\mathrm{Nt}$, nucleotide; aa, amino acid; KRAS, KRAS proto-oncogene, GTPase; $B R A F$, B-Raf proto-oncogene, serine/threonine kinase.

Statistical analysis. Statistical analyses were performed using IBM SPSS Statistics Version 20 (IBM SPSS, Armonk, NY, USA). As the dependent variable could be assumed to be normally distributed, a Jocheere-Terpstra test was used for testing the difference in the relative CK20 levels between TNM stages. Fisher's exact test was used for comparing the presence of specific tumor mutations in the peripheral blood, vascular invasion and lymphatic infiltration between TNM stages. A Mann-Whitney test was used for testing the difference between the levels of CK20 in groups described as R0 and R2 resections. Fisher's exact test was used for testing the difference in the change patterns of tumor mutations between the groups described as $\mathrm{R} 0$ and $\mathrm{R} 2$ resections. $\mathrm{P}<0.05$ was considered to indicate a statistically significant difference.

\section{Results}

Detection of tumor-specific DNA mutations. In 35/65 patients, the primary tumor tested positive for the specific mutations (KRAS mutations in codons 12, 13,61, 117 and 146, and BRAF mutations in codon 600) (Table II). In all these patients, the specimen of normal bowel resected with the tumor was also tested for the presence of the same mutations in order to exclude the germ-line mutations. Only patients who tested positive for the specific mutation in the primary tumor were included in further analysis (Fig. 1).

The mean age of the 35 mutation-positive patients was 68 years (range, 43-83 years), and 21 (60\%) of the patients were male and $14(40 \%)$ were female.

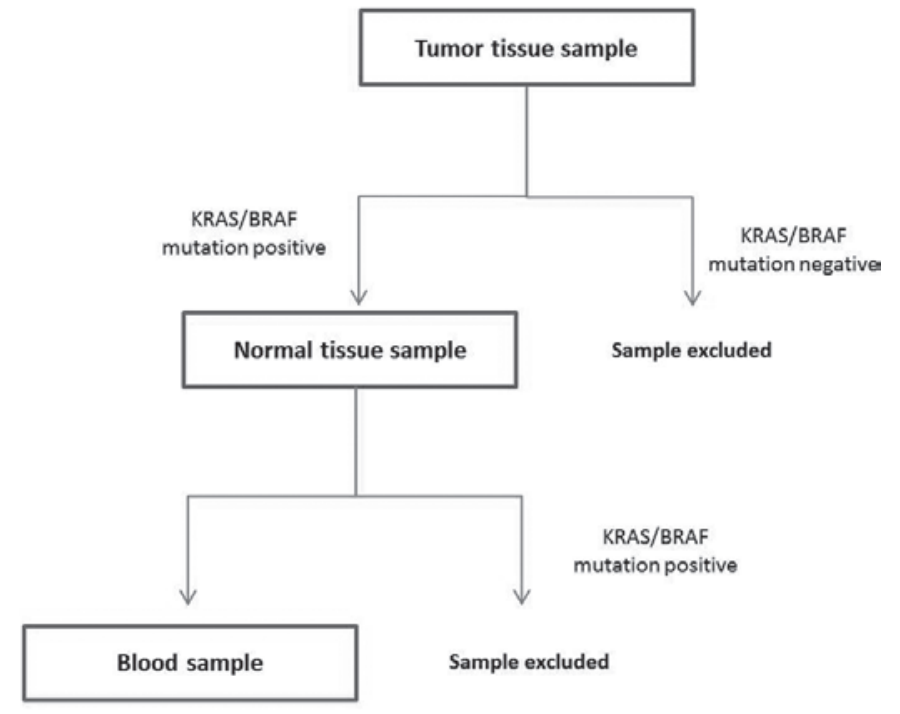

Figure 1. Schedule of $K R A S / B R A F$ mutation testing. For each patient, the $K R A S / B R A F$ mutation status was first determined in the tumor tissue sample. When a mutation was detected, the normal tissue sample was tested to exclude the samples with the germ-line mutation. When the normal tissue was negative (wild-type), the blood samples were tested for the presence of the KRAS/BRAF mutation determined in the matched tumor tissue sample. $K R A S$, KRAS proto-oncogene, GTPase; BRAF, B-Raf proto-oncogene, serine/threonine kinase.

The stage distribution of these 35 patients was 4,14 , 8 and 5 patients in UICC stages I, II, III and IV, respectively. In 4 patients, the resected specimen turned out to be a non-malignant adenoma. A total of 14 tumors were located in the right colon or hepatic flexure, 3 tumors were located in the splenic flexure or left colon, 11 tumors were located in the sigmoid colon or in the region of rectosigmoid junction, and 7 tumors were located in the rectum. Only one of the rectal tumors was treated pre-operatively with $5 \times 5$ Gy short-course radiotherapy.

Regarding the radicality of surgery, there were $30 \mathrm{R} 0$ resections and $5 \mathrm{R} 2$ resections. The $\mathrm{R} 2$ resections were all due to non-resectable liver metastases. Overall, 8 (23\%) of the resections were performed laparoscopically and 27 (77\%) were performed using the classic surgical technique.

The same mutation as in the primary tumor was detected in the first blood sample of 11 patients (31\%). In the second blood sample, the same mutation as in the tumor was detected in 6 patients (17\%). Additionally, 2 of the patients who were negative for the mutation in the first blood sample were positive for the mutation in the second blood sample (Table II).

Tumor stage at the time of surgery. The median relative levels of CK20 were 1.91, 1.95, 2.05 and 2.17 for tumor stages I, II, III and IV, respectively. The differences in relative CK20 levels in the peripheral blood between the different UICC stages were not statistically significant $(\mathrm{P}=0.689)$.

The same specific mutation as in the primary tumors was found in the peripheral blood of 2 out of $4(50 \%)$ patients in stage I, in 3 out of 14 patients (21\%) in stage II, in 2 out of 8 patients $(25 \%)$ in stage III and in 3 out of 5 patients $(60 \%)$ in stage IV (Fig. 2). Vascular invasion was reported in 1, 3, 2 and 3 tumor specimens of stages I, II, III and IV, respectively. 
Table II. Type and distribution of KRAS/BRAF mutations in colorectal cancer patients.

\begin{tabular}{|c|c|c|c|c|}
\hline Sample & Tumor tissue & Normal tissue & $\begin{array}{l}\text { Blood sample } \\
\text { collected } \\
\text { prior to surgery }\end{array}$ & $\begin{array}{l}\text { Blood sample } \\
\text { collected 5-7 days } \\
\text { after surgery }\end{array}$ \\
\hline 1 & p.Gln61Arg & wt & wt & wt \\
\hline 2 & p.Gly12Asp & wt & wt & wt \\
\hline 3 & p.Gly12Asp & wt & wt & wt \\
\hline 4 & p.Gly12Arg & wt & wt & $\mathrm{wt}$ \\
\hline 5 & p.Gly12Ser & wt & $\mathrm{wt}$ & $\mathrm{wt}$ \\
\hline 6 & p.Gly12Asp & wt & wt & wt \\
\hline 7 & p.Gly12Asp & wt & wt & wt \\
\hline 8 & p.Gly12Asp & $\mathrm{wt}$ & p.Gly12Asp & wt \\
\hline 9 & p.Gly12Val & wt & p.Gly12Val & wt \\
\hline 10 & p.Gly12Val & wt & wt & $\mathrm{wt}$ \\
\hline 11 & p.Val600Glu & wt & $\mathrm{wt}$ & $\mathrm{wt}$ \\
\hline 12 & p.Val600Glu & wt & wt & wt \\
\hline 13 & p.Gly13Asp & wt & wt & wt \\
\hline 14 & p.Gln61His & wt & wt & p.Gln61His \\
\hline 15 & p.Gly12Asp & wt & p.Gly12Asp & wt \\
\hline 16 & p.Gly12Val & wt & p.Gly12Val & $\mathrm{wt}$ \\
\hline 17 & p.Gly12Asp & wt & wt & wt \\
\hline 18 & p.Gly12Asp & wt & wt & wt \\
\hline 19 & p.Gly12Asp & wt & wt & ND \\
\hline 20 & p.Gly12Cys & wt & p.Gly12Cys & p.Gly12Cys \\
\hline 21 & p.Gly12Val & wt & p.Gly12Val & wt \\
\hline 22 & p.Gly12Val & wt & p.Gly12Val & $\mathrm{wt}$ \\
\hline 23 & p.Gly12Cys & $\mathrm{wt}$ & wt & wt \\
\hline 24 & p.Val600Glu & wt & wt & wt \\
\hline 25 & p.Gln61His & wt & wt & wt \\
\hline 26 & p.Gln61His & wt & wt & wt \\
\hline 27 & p.Gly12Ser & wt & $\mathrm{wt}$ & wt \\
\hline 28 & p.Ala146x & wt & p.Ala146x & p.Ala146x \\
\hline 29 & p.Val600Glu & wt & wt & wt \\
\hline 30 & p.Gln61Leu & wt & wt & p.Gln61Leu \\
\hline 31 & p.Gly12Asp & wt & p.Gly12Asp & p.Gly12Asp \\
\hline 32 & p.Gln61His & wt & $\mathrm{wt}$ & $\mathrm{wt}$ \\
\hline 33 & p.Gly12Alaq & wt & wt & wt \\
\hline 34 & p.Gly12Asp & wt & p.Gly12Asp & wt \\
\hline 35 & p.Ala146x & wt & p.Ala146x & p.Ala146x \\
\hline
\end{tabular}

wt, wild-type; ND, not determined; $\mathrm{x}$, the type of amino acid is not determined (it is either p.Ala146Thr, p.Ala146Pro or p.Ala146Val). KRAS, KRAS proto-oncogene, GTPase; $B R A F$, B-Raf proto-oncogene, serine/threonine kinase.

Lymphocyte infiltration was reported in 3, 7, 3 and 3 tumor specimens of stages I, II, III and IV, respectively. The differences between UICC stages were not statistically significant regarding the proportion of tumor-specific mutations found in the peripheral blood, vascular invasion or lymphocyte infiltration ( $\mathrm{P}=0.491, \mathrm{P}=0.435$, and $\mathrm{P}=0.717$, respectively) (Table III).

In the group of patients with adenomas, the specific mutation was found in the peripheral blood of 1 out of 4 patients (25\%); the median level of CK20 was 1.68 (range, 1.28-1.84) (Fig. 2). Information on vascular invasion or lymphocyte infiltration was not provided in the pathohistological report.
Residual disease after surgery. In the group of patients with $\mathrm{R} 0$ resections, the specific mutations were found in the peripheral blood of $8 / 30$ patients $(27 \%)$ prior to surgery and in $3 / 30$ patients $(10 \%)$ after surgery. The median levels of CK20 were 1.82 (range, 0.97-3.73) prior to surgery and 2.34 (range, 1.11-11.29) after surgery. In the $\mathrm{R} 2$ resection group, the specific mutations in the peripheral blood were detected in $3 / 5$ of the patients $(60 \%)$ prior to and after surgery. The median levels of CK20 were 2.16 (range, 2.02-3.14) and 2.60 (range, $2.42-2.87$ ) prior to and after surgery, respectively. 
Table III. Correlation of tumor-node-metastasis stages with vascular invasion and lymphocyte infiltration in primary tumors, as well as with the presence of specific DNA mutations and CK20 in peripheral blood.

\begin{tabular}{lccccr}
\hline & \multicolumn{5}{c}{ Stage of colorectal cancer } \\
\cline { 2 - 6 } Factor & $\mathrm{I}(\mathrm{n}=4)$ & $\mathrm{II}(\mathrm{n}=14)$ & III (n=8) & IV (n=5) & P-value \\
\hline Vascular invasion, $\mathrm{n}(\%)$ & $1(25)$ & $3(21)$ & $2(25)$ & $3(60)$ & $0.435^{\mathrm{a}}$ \\
Lymphocyte infiltration, $\mathrm{n}(\%)$ & $3(75)$ & $7(50)$ & $3(38)$ & $3(60)$ & $0.717^{\mathrm{a}}$ \\
DNA mutation detected & $2(50)$ & $3(21)$ & $2(25)$ & $3(60)$ & $0.491^{\mathrm{a}}$ \\
Median (range) relative CK20 & $1.91(1.57-3.14)$ & $1.95(0.97-3.32)$ & $2.05(1.09-3.73)$ & $2.17(2.02-3.14)$ & $0.689^{\mathrm{b}}$ \\
\hline
\end{tabular}

${ }^{a}$ From Fisher's exact test. ${ }^{b}$ From Joncheere-Terpstra test (exact P-value) assuming increasing order of relative CK20 level with increasing tumor stage. CK20, cytokeratin 20.

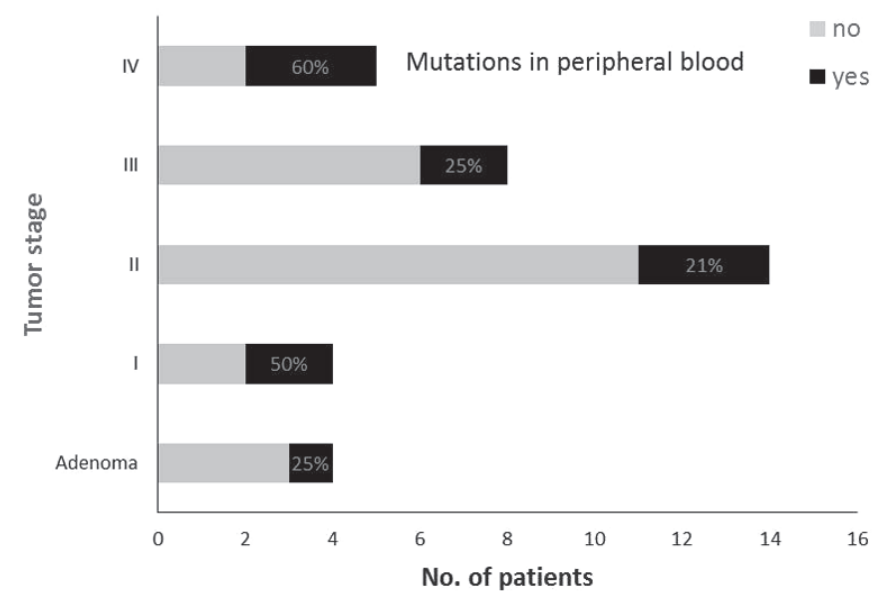

Figure 2. Percentage of patients with tumor-specific mutations in the peripheral blood.

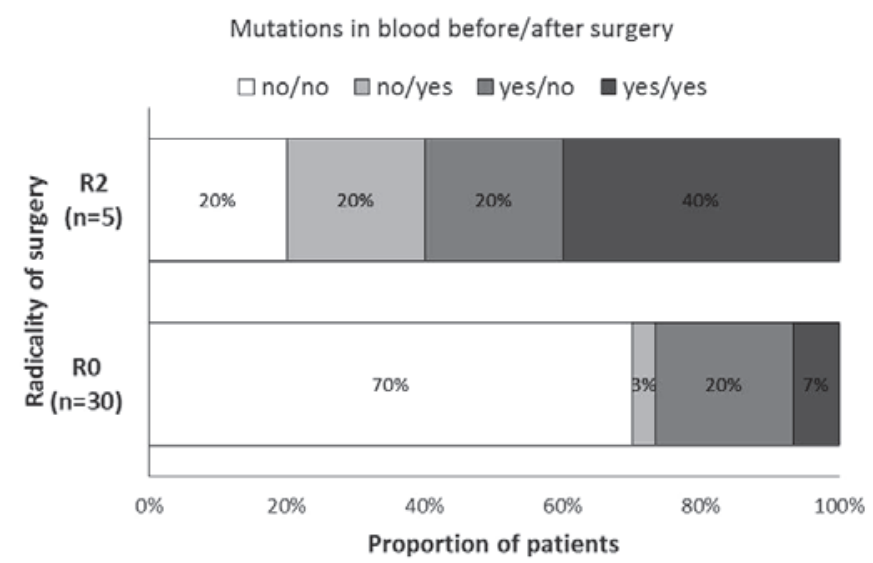

Figure 3. Percentage of patients with tumor-specific mutations in the peripheral blood prior to and following surgery in groups described as R0 and R2 resections.

The proportion of patients with the various patterns of tumor-specific mutations in the blood samples prior to and after the surgery was significantly different between the groups of patients described as R0 and R2 resections $(\mathrm{P}=0.038$, Fig. 3$)$. There was a higher proportion of patients with detected specific tumor mutations in each blood sample (collected prior to and after the surgery) in the R2 resection group.

The change in CK20 level was not statistically significantly different between the groups of patients described as $\mathrm{R} 0$ and $\mathrm{R} 2$ resection $(\mathrm{P}=0.671)$.

\section{Discussion}

According to the current understanding of tumor biology, the dissemination of the primary tumor is a complex process that occurs rather early in the course of the disease. It is known that numerous tumor cells are shed daily from the tumor even at early stages of the disease and that the majority of these cells die off very quickly in the peripheral circulation $(13,14)$. Therefore, it was first thought that the detection of circulating tumor cells (CTCs) in the peripheral blood would be the ultimate tool for monitoring the activity of the disease. However, the detection of CTCs turned out to be more complicated than expected. CTCs are extremely rare cells hidden in the background of numerous normal blood cells (15). From studies with proven metastatic CRC, it is known that only a few CTCs, if any at all, are found in standard blood probes (16). For the detection of CTCs, different molecular markers have been used, yet only some of them are specific for CTCs $(17,18)$. It was previously shown that specific DNA mutations found in tumors can mostly be found in metastases and also in isolated CTCs $(19,20)$. Therefore, it has been proposed that circulating free tumor DNA in the peripheral blood may be a good estimate of CTCs and of disease burden (21-23). It is expected that there should be no tumor DNA present in the circulation after the surgical removal of the whole tumor (24). The presence of tumor-specific DNA in the peripheral blood following primary tumor removal would be an indication of active metastatic sites in the patient's body, i.e., residual disease after surgery.

A few studies performed on CRC patients support the concept of serological staging by reporting a statistically significant association between CK20 levels or tumor-specific DNA mutations in the DNA from the peripheral blood and the tumor stage $(12,25-27)$. Therefore, the aim of the present study was to assess whether the detection of the expression of CK20 and the presence of $K R A S$ and $B R A F$ tumor-specific mutations in the peripheral blood can be used to determine the stage of a CRC patient prior to surgery and the $\mathrm{R}$ status after surgery. 
However, no statistically significant correlation could be found between the relative levels of CK20 or the presence of tumor-specific KRAS or BRAF mutations in DNA from the peripheral blood prior to surgery and the UICC disease stage. These results are in concordance with the results of numerous other studies that also failed to confirm the correlation between CK20, the presence of KRAS mutated or other tumor-derived DNA in the blood of CRC patients and the tumor stage (28-35). The present study was also not able to confirm a statistically significant correlation between residual disease after surgery, as described by R category, and CK20 levels in the blood prior to and following surgery.

However, statistically significant differences were found with regard to the proportions of patients with detected tumor-specific DNA mutations in the peripheral blood between the groups of patients with R0 and R2 resections. Statistical significance was associated with all patterns (combinations) of mutation presence in the blood samples prior to and following surgery. Tumor-specific DNA mutations in the peripheral blood were more frequently detected in the patients with incomplete surgical clearance of the tumor due to macroscopic residual disease ( $\mathrm{R} 2$ resections). In the literature, only scant and indirect data exist on the correlation of the radicality of surgery and the levels of molecular markers in the blood in the post-operative period (33). Studies mainly report solely on the detection rate of different molecular markers in the blood after surgery and focus on the tumor recurrence during the follow-up period $(29,32,35)$. A difference in pre- and post-operative levels of different molecular markers in the blood of patients operated upon for CRC has also been reported, yet with only an indirect correlation to the radicality of surgery $(36,37)$.

In the present study, tumor-specific DNA showed greater potential for residual disease detection than CK20. In theory, tumor-specific DNA also appears to be a more promising serological marker for tumor staging than non-specific epithelial markers, such as CK20. The main problem with using the detection of tumor-specific DNA in the peripheral blood for clinical use is the fact that there is no single tumor-specific mutation that can be found in all tumors of the same type (38). For CRC, for example, it is known that only up to $50 \%$ of all tumors have mutated KRAS (39). Even in proven mutated tumors the entire tumor cell population does not show specific mutations, but only certain portions of the tumor $(40,41)$. All of this has to be taken into account when interpreting the detection rates of specific tumor DNA mutations in the peripheral blood.

Despite conflicting evidence from previous studies, as well as the from results of the present study, the detection of tumor-specific DNA in the peripheral blood remains a promising, but highly challenging method for estimating the tumor burden at diagnosis and the residual disease after resection (42). The possibility of serological staging by the detection of tumor-specific DNA from the peripheral blood would be of great clinical importance in situations in which no tumor tissue is available for standard pathohistological staging. The important clinical issues of the residual disease after surgery, regression of the tumor after neoadjuvant or adjuvant treatment and the follow-up on watch-and-wait strategy of CRC patients with complete response after radiochemotherapy are all not assessable by pathohistological analysis (43). This fact is also recognized by the most recent, 7 th edition, of the
TNM classification, which moved away from the purely pathological to the clinicopathological staging in order to improve a number of the clinically apparent shortcomings of previous editions (44). With evolving diagnostic tools and treatment modalities, the concept of staging will inevitably drift away from the pathohistological analysis of the specimens even more in the future.

Overall, the present study concludes that the follow-up of somatic KRAS- and BRAF-mutated DNA in the peripheral blood of CRC patients may be useful in assessing the surgical clearance of the disease. Regardless of all the difficulties associated with the improvement of blood-specific DNA-based staging and the follow-up of CRC, the concept of serological staging may gain importance in the near future. Until then, good clinical and pathohistological staging and R category determination should remain the gold standard upon which all novel techniques are to be measured.

\section{References}

1. Brenner H, Kloor M and Pox CP: Colorectal cancer. Lancet 383: 1490-1502, 2014.

2. Pita-Fernández S, Alhayek-Aí M, González-Martín C, López-Calviño B, Seoane-Pillado T and Pértega-Díaz S: Intensive follow-up strategies improve outcomes in nonmetastatic colorectal cancer patients after curative surgery: A systematic review and meta-analysis. Ann Oncol 26: 644-656, 2015.

3. Compton CC: Colorectal carcinoma: Diagnostic, prognostic, and molecular features. Mod Pathol 16: 376-388, 2003.

4. Wittekind C, Compton CC, Greene FL and Sobin LH: TNM residual tumor classification revisited. Cancer 94: 2511-2516, 2002.

5. Wittekind C: Problems with residual tumor classification, particularly R1. Chirurg 78: 785-791, 2007 (In German).

6. Greene FL: Cancer staging in outcomes assessment. J Surg Oncol 110: 616-620, 2014

7. Nicholls J: Commentary. Colorectal Dis 14: 1074-1075, 2012.

8. Tsouma A, Aggeli C, Pissimissis N, Lembessis P, Zografos GN and Koutsilieris M: Circulating tumor cells in colorectal cancer: Detection methods and clinical significance. Anticancer Res 28: 3945-3960, 2008.

9. Sergeant G, Penninckx F and Topal B: Quantitative RT-PCR detection of colorectal tumor cells in peripheral blood-a systematic review. J Surg Res 150: 144-152, 2008.

10. Peach G, Kim C, Zacharakis E, Purkayastha S and Ziprin P: Prognostic significance of circulating tumour cells following surgical resection of colorectal cancers: A systematic review. Br J Cancer 102: 1327-1334, 2010.

11. Rahbari NN, Aigner M, Thorlund K, Mollberg N, Motschall E, Jensen K, Diener MK, Büchler MW, Koch M and Weitz J: Meta-analysis shows that detection of circulating tumor cells indicates poor prognosis in patients with colorectal cancer. Gastroenterology 138: 1714-1726, 2010.

12. Shen CX, Hu LH, Xia L and Li YR: Quantitative real-time RT-PCR detection for survivin, CK20 and CEA in peripheral blood of colorectal cancer patients. Jpn J Clin Oncol 38: 770-776, 2008.

13. Weinberg RA: Leaving home early: Reexamination of the canonical models of tumor progression. Cancer Cell 14: 283-284, 2008.

14. Klein CA: Cancer. The metastasis cascade. Science 321: 1785-1787, 2008.

15. Allan AL and Keeney M: Circulating tumor cell analysis: Technical and statistical considerations for application to the clinic. J Oncol 2010: 426218, 2010.

16. Cohen SJ, Punt CJ, Iannotti N, Saidman BH, Sabbath KD, Gabrail NY, Picus J, Morse MA, Mitchell E, Miller MC, et al: Prognostic significance of circulating tumor cells in patients with metastatic colorectal cancer. Ann Oncol 20: 1223-1229, 2009.

17. Dotan E, Cohen SJ, Alpaugh KR and Meropol NJ: Circulating tumor cells: Evolving evidence and future challenges. Oncologist 14: 1070-1082, 2009.

18. Maheswaran S and Haber DA: Circulating tumor cells: A window into cancer biology and metastasis. Curr Opin Genet Dev 20: 96-99, 2010. 
19. Knijn N, Mekenkamp LJ, Klomp M, Vink-Börger ME, Tol J, Teerenstra S, Meijer JW, Tebar M, Riemersma S, van Krieken JH, et al: KRAS mutation analysis: A comparison between primary tumours and matched liver metastases in 305 colorectal cancer patients. Br J Cancer 104: 1020-1026, 2011.

20. Mostert B, Jiang Y, Sieuwerts AM, Wang H, Bolt-de Vries J, Biermann K, Kraan J, Lalmahomed Z, van Galen A, de Weerd V, et al: KRAS and BRAF mutation status in circulating colorectal tumor cells and their correlation with primary and metastatic tumor tissue. Int J Cancer 133: 130-141, 2013.

21. Pantel $\mathrm{K}$ and Alix-Panabières $\mathrm{C}$ : Real-time liquid biopsy in cancer patients: Fact or fiction? Cancer Res 73: 6384-6388, 2013.

22. Bidard FC, Weigelt B and Reis-Filho JS: Going with the flow: From circulating tumor cells to DNA. Sci Transl Med 5: 207ps14, 2013.

23. Bettegowda C, Sausen M, Leary RJ, Kinde I, Wang Y, Agrawal N, Bartlett BR, Wang H, Luber B, Alani RM, et al: Detection of circulating tumor DNA in early- and late-stage human malignancies. Sci Transl Med 6: 224ra24, 2014.

24. Diehl F, Schmidt K, Choti MA, Romans K, Goodman S, Li M, Thornton K, Agrawal N, Sokoll L, Szabo SA, et al: Circulating mutant DNA to assess tumor dynamics. Nat Med 14: 985-990, 2008.

25. Iinuma H, Okinaga K, Egami H, Mimori K, Hayashi N, Nishida K, Adachi M, Mori M and Sasako M: Usefulness and clinical significance of quantitative real-time RT-PCR to detect isolated tumor cells in the peripheral blood and tumor drainage blood of patients with colorectal cancer. Int J Oncol 28: 297-306, 2006.

26. Tsouma A, Aggeli C, Lembessis P, Zografos GN, Korkolis DP, Pectasides D, Skondra M, Pissimissis N, Tzonou A and Koutsilieris M: Multiplex RT-PCR-based detections of CEA, CK20 and EGFR in colorectal cancer patients. World J Gastroenterol 16: 5965-5974, 2010

27. Lin JK, Lin PC, Lin CH, Jiang JK, Yang SH, Liang WY, Chen WS and Chang SC: Clinical relevance of alterations in quantity and quality of plasma DNA in colorectal cancer patients: Based on the mutation spectra detected in primary tumors. Ann Surg Oncol 21 (Suppl 4): S680-S686, 2014.

28. Wang JY, Wu CH, Lu CY, Hsieh JS, Wu DC, Huang SY and Lin SR: Molecular detection of circulating tumor cells in the peripheral blood of patients with colorectal cancer using RT-PCR: Significance of the prediction of postoperative metastasis. World J Surg 30: 1007-1013, 2006.

29. Uen YH, Lu CY, Tsai HL, Yu FJ, Huang MY, Cheng TL, Lin SR and Wang JY: Persistent presence of postoperative circulating tumor cells is a poor prognostic factor for patients with stage I-III colorectal cancer after curative resection. Ann Surg Oncol 15: 2120-2128, 2008.

30. Ryan BM, Lefort F, McManus R, Daly J, Keeling PW, Weir DG and Kelleher D: A prospective study of circulating mutant KRAS2 in the serum of patients with colorectal neoplasia: Strong prognostic indicator in postoperative follow up. Gut 52: 101-108, 2003.
31. Hsieh JS, Lin SR, Chang MY, Chen FM, Lu CY, Huang TJ, Huang YS, Huang CJ and Wang JY: APC, K-ras, and p53 gene mutations in colorectal cancer patients: Correlation to clinicopathologic features and postoperative surveillance. Am Surg 71: 336-343, 2005 .

32. Frattini M, Gallino G, Signoroni S, Balestra D, Lusa L, Battaglia L, Sozzi G, Bertario L, Leo E, Pilotti S and Pierotti MA: Quantitative and qualitative characterization of plasma DNA identifies primary and recurrent colorectal cancer. Cancer Lett 263: 170-181, 2008.

33. Lecomte T, Ceze N, Dorval E and Laurent-Puig P: Circulating free tumor DNA and colorectal cancer. Gastroenterol Clin Biol 34: 662-681, 2010.

34. Kopreski MS, Benko FA, Borys DJ, Khan A, McGarrity TJ and Gocke CD: Somatic mutation screening: Identification of individuals harboring K-ras mutations with the use of plasma DNA. J Natl Cancer Inst 92: 918-923, 2000.

35. Lu CY, Uen YH, Tsai HL, Chuang SC, Hou MF, Wu DC, Juo SH, Lin SR and Wang JY: Molecular detection of persistent postoperative circulating tumour cells in stages II and III colon cancer patients via multiple blood sampling: Prognostic significance of detection for early relapse. Br J Cancer 104: 1178-1184, 2011.

36. Allen-Mersh TG, McCullough TK, Patel H, Wharton RQ, Glover C and Jonas SK: Role of circulating tumour cells in predicting recurrence after excision of primary colorectal carcinoma. Br J Surg 94: 96-105, 2007.

37. Lindforss $\mathrm{U}$, Zetterquist $\mathrm{H}$, Papadogiannakis $\mathrm{N}$ and Olivecrona $\mathrm{H}$ : Persistence of K-ras mutations in plasma after colorectal tumor resection. Anticancer Res 25: 657-661, 2005.

38. Wood LD, Parsons DW, Jones S, Lin J, Sjöblom T, Leary RJ, Shen D, Boca SM, Barber T, Ptak J, et al: The genomic landscapes of human breast and colorectal cancers. Science 318: 1108-1113, 2007.

39. Ličar A, Cerkovnik P and Novaković S: Distribution of some activating KRAS and BRAF mutations in Slovene patients with colorectal cancer. Med Oncol 28: 1048-1053, 2011

40. Gerlinger M, Rowan AJ, Horswell S, Larkin J, Endesfelder D, Gronroos E, Martinez P, Matthews N, Stewart A, Tarpey P, et al: Intratumor heterogeneity and branched evolution revealed by multiregion sequencing. N Engl J Med 366: 883-892, 2012.

41. Bork U, Grützmann R, Rahbari NN, Schölch S, Distler M, Reissfelder C, Koch M and Weitz J: Prognostic relevance of minimal residual disease in colorectal cancer. World J Gastroenterol 20: 10296-10304, 2014.

42. Yong E: Cancer biomarkers: Written in blood. Nature 511: 524-526, 2014

43. Chapuis PH, Bokey L, Chan C and Dent OF: Colorectal cancer staging revisited: Time for critical evaluation? Colorectal Dis 14: 1043-1044, 2012

44. Wittekind C and Oberschmid B: TNM classification of malignant tumors 2010: General aspects and amendments in the general section. Pathologe 31: 333-334, 336-338, 2010 (In German). 